\title{
The Effective Action of Theatre in the Educational Mapping of Linguistic and Intercultural Mediators ${ }^{1}$
}

\author{
María Isabel Fernández García, Mercedes Ariza, Claudio \\ Bendazzoli, Maria Giovanna Biscu, Yvonne Grimaldi
}

1. This paper is based on an earlier and more extensive version in Spanish entitled 'El aula de teatro universitario en la formación de mediadores lingüísticos interculturales: intersecciones entre teoría y experiencia' (Fernández, Ariza 2011) and published in Villalba, F. and J. Villatoro (eds.) (2011): Educación intercultural y enseñanza de lenguas. Vol. 3. Málaga: Prácticas en Educación. Edición digital Letra 25, 22-33. The present version was edited and summarized by all the authors (María Isabel Fernández García wrote §2, §2.1, Mercedes Ariza §3, Claudio Bendazzoli §1, §2.3, Maria Giovanna Biscu §2.2 and Yvonne Grimaldi §2.4; the conclusions were jointly drafted) and translated into English by Claudio Bendazzoli.

\begin{abstract}
This paper is based on the University Theatre experience at the Advanced School of Modern Languages for Interpreters and Translators (SSLMIT) of the University of Bologna (Forlì campus) over the last twenty years. A great number of trainee translators and interpreters has had the opportunity to explore the world of theatre in a foreign language, which can be referred to as TiLLiT (i.e. theatre in language and language in theatre) or stage-classroom. This activity has been carried out within a comprehensive educational context, enabling participants to acquire both general and specific competences, as suggested in the European Higher Education Area. Evidence of this can be found in the final dissertations that some students-actors wrote to complete their curriculum. Four dissertations in total will be considered to illustrate the effective action of theatre, which enables its main protagonists to establish a direct link between theoretical notions and experience.
\end{abstract}

\section{Introduction}

The aim of the present paper is to show the value of university theatre in second language teaching/learning and, more specifically, in the acquisition of the intercultural communicative competence (Fernández García et al. 2009) by illustrating to what extent university theatre had an impact on the curriculum of four undergraduates at the Advanced School of Modern Languages for 
Interpreters and Translators (SSLMIT) of the University of Bologna (Forlì campus). Indeed, this has been the object of reflection and observation for several years within the university theatre groups of SSLMIT, where an intense theatrical activity has been going on since $1992 .^{2}$ This activity is carried out within a comprehensive educational context, enabling participants to acquire both general and specific competences, as suggested in the European Higher Education Area (González \& Wagenaar 2006). After nearly twenty years of theatre in a foreign language, it has been possible to observe and acknowledge that the experience gained on the stage-classroom makes it possible to transform theoretical notions of the academic curriculum into know-how. Evidence of this can be found in the final dissertations by some students-actors. The theoretical insights proposed by the students themselves are particularly significant, as they are focused on tangible signs of the existing shared ground between trainees' stage experience, the development of the intercultural communicative competence, and their future as linguistic mediation professionals.

In the present paper, four dissertations in total will be considered. These were produced during a three-year project, which was organised by the Centre for Theatre Studies of the Department of Multidisciplinary Studies in Translation, Languages and Cultures (SITLeC, University of Bologna, Forlì campus). The project was entitled 'The stage-classroom in linguistic and cultural mediator education. A harbour for discoverers of otherness' (or, more simply, Discoverers) ${ }^{3}$ and was structured into three main stages, namely (1) Discovering the other, (2) Talking to the other, and (3) Listening to the other. Each year corresponded to one stage and a number of undergraduates were involved in its development and research activities, as there was a direct link between the project itself and the university theatre experience of the Spanish group at SSLMIT.

\section{The stage-classroom: a space to develop mental plasticity}

University theatre in a foreign language stands as a concrete answer to the needs posed by the European Higher Education Area (EHEA), its main priority being based on an educational model to teach students how they can learn, i.e. acquiring the skills to achieve the following objective: learning to learn. Within the context of the EHEA, L2 teaching/learning has stimulated a debate on determining which methodologies are most suited to acquire, in an efficient way, both linguistic skills and the intercultural communicative competence. The present work is relevant to this debate starting from a concrete scenario:

\footnotetext{
${ }^{2}$ In the academic year 2010-2011, the University Theatre at SSLMIT included eight different groups, each of which set up a performance in one of the following languages: French, Spanish, English, German, Japanese, Slovak, Bulgarian and Portuguese (see the webpage of the Centro di Studi Teatrali - Centre for Theatre Studies http://www.centrodistuditeatrali.it).

3 The original title of the project is in Spanish: 'El aula-escenario en la formación de futuros mediadores lingüísticos: un puerto para descubridores de la otredad' or 'Descubridores' (Fernández García Biscu 2005-2006; 2008).
} 
linguistic and intercultural mediator training at the SSLMIT of the University of Bologna at Forlì. ${ }^{4}$

Transferable competences are considered a critical part of interpreter and translator training (see, for instance, Kalina 2000). Indeed, such skills are a priority in any professional field and can guarantee life-long learning, because they last throughout time. As will be highlighted in the following sections, the stage-classroom and university theatre give students the opportunity to tap on multiple resources and skills at the same time, thus taking advantage of experience-based learning and adding value to their knowledge base.

University theatre activities at SSLMIT have always been carried out on a voluntary basis by both students and staff as an extra-curricular activity. Interested students must be members of a students' society called SSenzaLiMITi ${ }^{5}$ which can apply for financial support from the University. The local Department and the Centre for Theatre Studies also sponsor the TiLLiT initiatives, and some members of staff take part as facilitators in some groups. Depending on students' availability and interest, every year there can be more or less university theatre groups in any of the languages that are taught and studied at SSLMIT (i.e. Italian, French, German, English, Russian, Spanish, Bulgarian, Arabic, Slovak, Portuguese, Japanese, Finnish). Moreover, the Department organizes workshops that are open to all students, particularly to those involved in TiLLiT, and supports the groups that may require the advice of external experts (e.g. choreographers, directors, professional actors and so on). Each group holds weekly meetings and rehearsals from the beginning of the academic year in October until May, when all the final performances are staged in a festival lasting two or three evenings, depending on the number and duration of TiLLiT shows. The festival is open not only to the students of the local campus, but also to any other student, university staff and ordinary citizens. Indeed, this festival has become part of a wider programme of cultural initiatives and events, which are organized and held in collaboration with both academic and community-based institutions.

The university theatre groups can select any text or subject to be put on stage (sometimes a common theme is agreed in advance); some groups may even be involved in research projects, as was the case with the specific examples described in this paper. ${ }^{6}$

In the following sub-sections, the TiLLiT experience of four undergraduates at SSLMIT - Luciano Baldan, Angelo Nestore, Dalila Crobu and Eleonora Gentili - will be illustrated, taking their final dissertation work into account. Their

\footnotetext{
4 The SLLMIT (Advanced School of Modern Languages for Interpreters and Translators) offers one BA-equivalent programme in Cultural and Linguistic Mediation (three year undergraduate degree course) and two MA-equivalent programmes (two year postgraduate degree programmes) in Translation and in Conference Interpreting (further details are available on its webpage http://www.ssit.unibo.it).

5 The name 'SSenzaLiMITi' is a pun on SSLMIT and literally means 'without limits'.

6 For more details on the TiLLiT activities at SSLMIT, see Fernández García et al. 2009 and the webpage of the Centre for Theatre Studies (Centro di Studi Teatrali) www. centrodistuditeatrali. it which includes the full archive of the shows performed every year.
} 
projects dealt with the use of IT in language mediation and theatre, university theatre and translation skills, the role of Malinche in mediator training, and the exile experience in theatre and interpreter training.

\subsection{Theatre and Information Technology}

The work by Luciano Baldan (2008) is entitled 'Educational routes to discover the other: language mediation, theatre and new technologies'. This is a multifaceted study in which multidisciplinarity and diverse personal interests converged on the stage-classroom. Luciano Baldan had obtained a BA in Information Technology in 2004, with a project on virtual environments on the Internet. After that, he also took a career in Translation and Interpreting (BA at SSLMIT), where he played an active role in the above mentioned research project called 'Discoverers' (stage 1 and 2): he decided to carry out his internship within that project, collaborating with the State Prison in Forlì, the Respite Centre of the local Mental Health Unit, the 'Dante Alighieri' primary school and 'Felice Orsini' secondary school. Against this background, he played a number of roles: actor, web designer, musician, composer, playwright, intercultural mediator and theatre coach. In the conclusions of his theoretical work, Baldan advanced that all the activities involved in the stage-classroom helped him transform the theoretical notions acquired throughout his curriculum into concrete knowledge, in that real life experience was the missing link between theory and practice. This was a fundamental step to get closer to the job market and make the most of the skills developed during his training (Baldan 2008: 56).

The following is the route Baldan went through to achieve the conclusions mentioned above: starting from the training objectives established by Hurtado Albir (1999) in learning Spanish as a foreign language and practising dialogue interpreting, he reflected on the skills acquired and developed by means of the stage-classroom / TiLLiT method.

As regards language skills (Spanish as a foreign language), Baldan stated that he managed to further develop his understanding of read texts, identify language variation in texts, get familiar with the use of sources and documentation, and develop correct pronunciation and intonation.

As for dialogue interpreting-related skills, he enhanced his ability to pay attention and concentrate for long periods of time without interruptions, managed to develop split attention (auditory and visual), memory skills, promptness in responding to situations, physical and mental strength, and objective self-evaluation.

Eventually, his gradual acquisition of transferable skills has enabled him to have high employability: in 2011 he worked as translator and guitar trainer, teacher of English as L2, coordinator of a drama workshop in a primary and secondary school, and web designer for academic institutions (e.g. he designed web pages of research projects and international conferences).

As a final evaluation, two aspects in particular should be emphasised. Firstly, 
IT skills acquired in his first BA were strengthened and widened thanks to theatrical creativity. Secondly, he was led to discover one of the key factors in successful intercultural communication: taking part in the Discoverers project, Baldan felt that he had matured, professionally and personally, had become more aware of marginal situations and understood that communication is possible whenever an effort is made so that one is free of the barriers imposed by individualism.

Among the IT assignments accomplished by Baldan, the website of the Centre for Theatre Studies ${ }^{7}$ is an important resource available to any scholar and researcher. A wealth of information can be found on the cultural and scientific activities organised by the Centre itself. Moreover, this website includes an archive of the TiLLiT activities held at SSLMIT (1999-2009). Interestingly, cyberspace can help users challenge the ephemeral and transient nature of theatrical meetings and go beyond the borders of local stages.

\subsection{Theatre and Translation}

In his dissertation entitled 'The TiLLiT experience and translator training', Angelo Nestore (2008) addressed the role of artistic experience and, in particular, theatrical experience in the acquisition of translation skills. He took part in the third stage of the Discoverers project (i.e. listening to the other), thus making a comparison between two figures: the actor and the translator. $\mathrm{He}$ investigated to what extent his participation in university theatre in Spanish may have influenced the acquisition process of his translation competence.

According to Nestore, the TiLLiT experience triggered his motivation and interest in research, speeding up his learning time thanks to the activation of resources and skills such as memory, reflexes and, above all, creativity.

Generally, intensifying creative processes may influence one's personal dimension and future professional life. In this particular case, Nestore contributed to writing the script of a performance ('Twenty years are nothing') about the desaparecidos in Argentina. During this activity, he immersed himself in poetic writing in Spanish, and this led him to develop a profound interest in literary translation, with immediate consequences on his post-graduate education choices. After graduating in October 2008, Nestore attended a Master in Translation, Cultural Mediation and Interpreting at the University of Malaga (Spain) and then he enrolled on a $\mathrm{PhD}$ programme with a research project on the translation of subversion in graphic novels.

The theoretical framework adopted in his analysis was the holistic model of translation competence and the related sub-competences established by the PACTE research group (PACTE 2001: 41). ${ }^{8}$ Below is a summary of the results

\footnotetext{
7 The Italian full name of this centre is 'Centro di Studi Teatrali. Aula di Studi Scenici e Comunicazione Interculturale' (http://www.centrodistuditeatrali.it).

8 PACTE is the acronym for 'Proceso de Adquisición de la Competencia Traductora y Evaluación', i.e. Process of Acquisition of the Translation Competence and Evaluation (see website of this research group: http://grupsderecerca.uab.cat/pacte/en).
} 
reported by Nestore with reference to the skills he was able to strengthen thanks to his TiLLiT background:

communicative competence in twolanguages, especially textual, elocution and sociolinguistic competence;

extralinguistic competence: bicultural and encyclopedic knowledge;

instrumental/professional competence: knowledge and use of documentation sources, organisational skills and ability to work in a team;

psycho-physiological competence: ability to apply psychomotor, cognitive and behavioural resources;

transfer competence: ability to go through the whole transfer process from an original text up to a translated text;

strategic competence: conscious and unconscious, verbal and non verbal processes that are used to solve problems found in the development of the translation process.

Many of the skills listed above are surely common to any other translation trainee. However, Nestore pointed out that the TiLLiT experience considerably intensified his motivation and helped him speed up his learning process, in that he was led to reflect upon and directly experience the translation process, thus shifting his focus from a purely linguistic dimension to the cultural and emotional side of source/target texts (Nestore: 58-59).

\subsection{Theatre and Intercultural Mediation}

In her final dissertation 'The role of Malinche in linguistic and cultural mediator training: theatrical experiences' (2009), Dalila Crobu focused on how the relationship between her persona as character and her persona as person could become a source of (self) training and learning. She studied the 'first' mediator ever, known as La Malinche, but also as Doña Marina or 'lengua', i.e. language - a term used by native people and conquerors to refer to interpreters, and analysed to what extent the character she had interpreted and played twice on the stage had influenced her as a person and as a learner.

La Malinche enabled her to create a space at the edge, i.e. to develop a personal observation point for her and her peers' training as language and intercultural mediators. From this theatrical vantage point she was able to become more aware of her own identity and culture, thus developing the ability to understand the views of the other. Interesting observations can be found in this work, e.g. when Crobu mentions that it is not possible to accept the other's cultural paradigms if one has a mono-cultural mind. In this respect, enhancing one's mental flexibility can be the key to gain access to multicultural encounters. 
The entire work was based on her two-year TiLLiT experience. In her first performance in 2007 she acted as 'interpreter of indigenous people' in a comedy by Lope de Vega (The New World Discovered by Christopher Columbus). Her character was Palca-Malinalli Tenépatl, a young native of the new world who welcomed the invaders on Baracoa beach. She discovered the notion of identity in diversity when she saw her image reflected in a mirror she was given by the Spaniards. This 'powerful' theatrical object triggered different communicative reactions, leading to both success and failure, but above all it magnified the profound gap generated by the encounter with the other.

The new territory explored as Palca - the character, together with the three dimensions you/I/we -, made it possible for Dalila to engage in a second performance called 'Labyrinths' (Fernández, Bendazzoli, Biscu 2008), based on texts by Octavio Paz. Here she played a 'triple' character: Doña Marina+Malinche+Capitán Malinche/Cortés. The poet of otherness (Paz 1961 , 1993) provided her with a scenario in which she also acted as a mediator between the members of the drama group, thus softening conflicts and networking experiences so that, eventually, the way out of the labyrinth could be found both on and off stage.

Eventually, a significant observation resulting from Crobu's TiLLiT experience is that when the curtain was lowered at the end of the show "I realised that by performing as Palca I was able to develop mediation skills in such a way that no textbook about interpreting theory could have ever taught me" (Crobu 2008: $58)$.

Such a personal conclusion is well in line with the theoretical framework designed by Luigi Anolli in his essay La mente multiculturale dealing with the multicultural mind. Thanks to experience/performance, the intercultural actor has the possibility to train himself/herself and shape a multicultural mind, i.e. a versatile, open and complex mind, which is tolerant and pluralist, able to benefit from diverse emotional patterns in order to manage interpersonal relations and avoid communicative wrecks (Anolli 2006: 19).

\subsection{Theatre and Exile}

Eleonora Gentili wrote her final dissertation upon completion of a four-year degree course in Conference Interpreting. The title of her work is "The exile experience in linguistic-cultural mediator training. Theatre and inter-culture" (Gentili 2007). She examined the new professional figure of linguistic and cultural mediators within the framework of intercultural communication and ethno-empathy theory. She defined the set of necessary skills of a profession aimed at building communicative bridges, in contexts involving multiple ethnicities and cultures. The interaction of social, economic and institutional actors with ethnic and cultural differences entails conflict resolution and mediation between interested parties, so as to favouring their living together and mutual awareness. As a prerequisite of effective professional practice (in legal, administrative, business, health care and sociocultural contexts), Gentili 
decided to focus on the issue of wandering and exile in the human condition, proposing this as a heuristic tool to understand the current forms of dis/location, which are fundamental in a century characterised by cultural and geographical displacement. Against this background, it seems that by acknowledging the nomadic condition of human beings it was possible to develop the empathetic competence, thus achieving active listening and awareness of the other, be it an economic exile or a manager. This appears to be the only way to accomplish authentic intercultural mediations.

The study by Gentile confirmed the hypothesis whereby the TiLLiT experience can favour the acquisition of the ethno-empathetic competence, which is essential to understand dis/location and dis/placement phenomena. To this end, she analyzed the process experienced by two students who took part in the Spanish TiLLiT and performed 'Two exiles' (in May 2006) from 'Terror and Misery in the First Franco' by José Sanchis Sinisterra (Gentili 2007: 158-162). The students involved played the role of two brothers, Jorge and Leandro, who were living two different exile conditions (i.e. the former was in a 'geographical' or 'physical' exile, as Jorge had moved from Spain to Mexico after the Spanish Civil War; on the other hand, Leandro was living in a sort of inner, more psychological exile: he remained in Spain but had lost his freedom as he had been a supporter of the Republican faction).

Besides studying the script, the two students-actors researched background information to build up their characters. For instance, they collected images and tunes pertaining to the relevant historical period; they also interviewed their grandparents and other relatives to retrieve a collective memory on life during Fascism and the Second World War. All these elements gave them the chance to directly experience an issue (on stage) they had only read about or studied as 'something' that has been present 'sometimes' and 'somewhere' in history. Indeed, they admitted that they were also able to recall and recognise a wider array of feelings and emotional 'signs' related to the exile experience even in their personal lives (Gentili 2007: 158-162).

As a final result, it was possible to conclude that both students-actors had a comprehensive experience in their body-mind of the universal human condition of exile. For this reason, they were able to recognize it and recall it in their daily lives, prior to and after the show. Their life on the stage, in turn, allowed them to listen to and recognize the voice of the other embedded in themselves. In this respect, one of the most significant conclusions is that the training potential of theatre can be found in the authenticity of theatrical fiction, as stage pretence can reveal the truth of reality. Such a potential may ensure and explain the acquisition of the empathetic competence, which can make linguistic mediations authentic and honest - an alternative perspective on what is usually considered a faithful vs. unfaithful translation or translator. Furthermore, the empathetic competence is likely to strengthen compliance with professional codes of conduct. 


\section{Assessment}

In order to assess the comprehensive and integrating methodology adopted in the stage-classroom, the criteria designed by Fernández March (2006: 50) were taken into account. These are based on five variables, which were proposed by Prégent (1990) with the objective to providing trainers with the opportunity to select a suitable teaching method for the competences they aim to strengthen and stimulate: (1) Level of cognitive objectives; (2) Favouring autonomous and long lasting learning; (3) Degree of control over one's learning experience; (4) Number of participants; (5) Number of working hours.

(1) The level of cognitive objectives is higher, as this methodology makes it possible to shift from the lower levels found in Bloom's taxonomy (i.e. knowing, understanding and applying) to the higher levels, which include analysing, synthesising and evaluating (Bloom 1990). In all the case studies considered above, students with a TiLLiT background decided to take their university theatre experience to a higher level and write their final dissertation on a research subject that was fully relevant to their TiLLiT experience. In some cases, this even had an impact on their professional development or postgraduate education choices.(2) The capacity of TiLLiT to favour autonomous and life-long learning is high, in that students become more responsible in planning and fulfilling learning tasks. Each performance could be considered as a 'module' according to the task-based learning approach, including workshops and seminars, which help students accomplish their theatrical task (eventually, the audience response will shed light on the students' level of preparation and autonomy). Moreover, students have little time, and a considerable effort is demanded from them to take part in the TiLLiT activities. Indeed, these activities are carried out in the evening or at night, entirely on a voluntary basis as no credits are awarded. However, students do not seem to be discouraged and show even a greater motivation to learn, even more so as they get closer to the end of their TILLIT experience.(3) The degree of students' control over their learning is high. By acting autonomously and expressing creativity, students play a protagonist role in their learning process. Although they may receive some guidance and suggestions from teaching staff, the latter are perceived as facilitators who can share knowledge and provide inputs, which will then be managed by the students themselves. Indeed, they contribute to content creation through their ideas, interests and reactions to the group's decisions. They feel personal involvement and take advantage of teamwork to fulfil a variety of tasks (Fonio \& Genicot 2011: 79), increasing their awareness of the resulting beneficial effects on their future professional lives. In many cases, given the emotional impact of TiLLiT, this experience has been considered fundamental to achieve greater self-esteem - a key aspect in learning (Gargallo López 2006). As stated above, university theatre at SSLMIT has always been an extra-curricular activity and is managed directly by students. Only some groups are also helped by staff members, who play the role of facilitators and guarantee continuity (though many students take part in university theatre every year 
throughout their curriculum, they may be involved in exchange programmes, study placements abroad, internships and so on).(4) The number of students to be involved, i.e. the size of the working group, is medium, ranging from 15 to maximum 30 participants. However, there have also been groups of just two or three students. Such a great variation is mostly due to the fact that the full curriculum is available for a limited number of languages (i.e. English, French, German, Spanish and Russian), and this has an impact on the potential number of available students. (5) The amount of working time required (i.e. preparation, rehearsal, meetings and corrections/revisions) is high. University theatre usually starts at the beginning of the academic year in October and ends with a final public performance in May. As a consequence, the stage-classroom includes several meetings with students and, above all, a great number of hours to be spent in research and preparation of materials, as well as stage setting and costumes. All this (extra) work for corrections and revision of students' theatrical activity is bound to increase towards the end of the academic year, when more and more meetings and rehearsals are necessary.

\section{Concluding remarks}

In this paper four final dissertations by trainee translators and interpreters who took part in university theatre at SSLMIT were illustrated to highlight the effective action of (university) theatre (in a foreign language) on future professional intercultural mediators. Indeed, the flexible and collaborative dimension of the stage-classroom seems to be particularly suited to successfully meet the challenges posed by the rapidly changing environment of higher education.

In each of the four cases presented above, the students were able to take advantage of the TiLLiT experience, pointing out a great number of skills and transferring them from the university theatre workshop or the stage to their professional life. In particular, they emphasised the key role of university theatre in linking the theoretical notions acquired throughout their curriculum to know-how and real life experience. Given the crucial role of transferable skills, these four final dissertations stand as a valuable tool to promote university theatre in different learning environments and stimulate students to become independent learners.

\section{Bibliography}

Anolli, Luigi (2006): La mente multiculturale. Roma-Bari: Laterza

Baldan, Luciano (2008): Percorsi formativi per la scoperta dell'altro: mediazione linguistica, teatro e nuove tecnologie. Unpublished BA thesis, University of Bologna at Forlì [http://www. centrodistuditeatrali.it/ public/tempospazio/tesi/LucianoBaldan.pdf , last accessed 11/09/2012] 
Bloom, Benjamin (1990): Taxonomía de los objetivos de la educación. La clasificación de las metas educacionales. Buenos Aires: El Ateneo

Crobu, Dalila (2009): El 'papel' de La Malinche en la formación del mediador lingüístico y cultural: experiencias teatrales. Unpublished BA thesis, University of Bologna at Forlì

Fernández García, María Isabel; Biscu, Maria Giovanna (2005-2006): Theatre in the Acquisition of Intercultural Communicative Competence: The Creation of a Multilingual Corpus of Dramatic Texts for the Training of Future Language Mediators. In: International Journal of Learning 12/10, 327-335

Fernández García, María Isabel; Biscu, Maria Giovanna (2008): Intercultural Settings for Language Mediation: Evaluation of a Research Project on Language Mediator Training Through Theatre, In: International Journal of Learning, 15/1, 51-63

Fernández García, María Isabel; Bendazzoli, Claudio; Biscu, Maria Giovanna (2008): Voces en busca de persona(je)s: ecos desde el laberinto de la soledad. In: Horne, S. Maria; Fediuk, Elka; Flores, Isabel Cristina; Larrue, Jean Marc (eds.) Identidad y sus lenguajes en el teatro universitario; paradigmas y paradojas. Memorias del VII Congreso Internacional de Teatro Universitario de la Asociación Internacional de Teatro Universitario (AITU-IUTA), en la Benemérita Universidad Autónoma de Puebla, México. 2-6 junio 2008. Puebla: BUAP, 38-48

Fernández García, María Isabel; Zucchiatti, Marie-Line; Biscu, Maria Giovanna (eds.) (2009): L'esperienza teatrale nella formazione dei mediatori linguistici e culturali. Bologna: Bononia University Press

Fernández March, Amparo (2006): Metodologías activas para la formación de competencias. In: Educatio Siglo 21/24, 35-56

[http://revistas.um.es/educatio/article/view/152/135, last accessed 11/09/2012]

Fonio, Filippo; Genicot, Geneviève (2011) The compatibility of drama language teaching and CEFR objectives - observations on a rationale for an artistic approach to foreign language teaching at an academic level. In: Scenario 5/2, 76-89

Gargallo López, Bernardo (2006): Autoconcepto y rendimiento académico en estudiantes universitarios. In: XXV Seminario interuniversitario de teoría de la educación 'Las emociones y la formación de la identidad humana' Universidad de Salamanca

[http://www.ucm.es/info/site/docu/25site/ad3gargallo.pdf, last accessed 11/09/2012]

Gentili, Eleonora (2007): L'esperienza dell'esilio nella formazione del mediatore linguistico-culturale. Teatro e interculturalità. Unpublished MA thesis, University of Bologna at Forlì [http://www.centrodistuditeatrali.it/ public/tempospazio/tesi/EleonoraGentili.pdf, last accessed 11/09/2012]. 
González, Julia; Wagenaar, Robert (eds.) (2006): Tuning Educational Structures in Europe. Final Report. Phase One. Bilbao: Universidad de Deusto/Universidad de Groningen

Hurtado Albir, Amparo (1999): Enseñar a traducir. Madrid: Edelsa Grupo Didascalia

Kalina, Sylvia (2000): Interpreting competences as a basis and a goal for teaching. In: The Interpreters' Newsletter 10, 3-32

[http://www.openstarts.units.it/dspace/handle/10077/2440, last accessed 11/09/2012]

Nestore, Angelo (2008): L'esperienza del laboratorio teatrale in lingua e la formazione del traduttore. Unpublished BA thesis, University of Bologna at Forlì PACTE, Grupo (2001): La competencia traductora y su adquisición. In:

Quaderns. Revista de Traducció 6, 39-45

Paz, Octavio (1961) The Labyrinth of Solitude: Life and Thought in Mexico; translated by Lysander Kemp. New York: Grove Press; London: Evergreen Books

Paz, Octavio (1993) El laberinto de la soledad. Madrid: Cátedra

Prégent, Richard (1990): La préparation d’un cours. Montréal: Éditions de l'École Polytechnique de Montréal 